\title{
Fuentes tomistas contemporáneas de la filosofía política: atisbos del paradigma tomasiano*
}

\section{Contemporary sources of thomistic political philosophy: hints of the thomistic paradigm}

\author{
Carlos Alberto Cárdenas Sierra \\ Édgar Antonio Guarín Ramírez***
}

\section{Resumen}

Con la ayuda de cuatro filósofos políticos tomistas contemporáneos (Copleston, Lachance, Maritain y Chalmeta), trazamos esbozos del paradigma de la filosofía política de Tomás de Aquino', que servirá de base para el diálogo con los filósofos políticos contemporáneos. El presente artículo integra, en este estado inicial de la investigación, dos ensayos: el primero presenta nuestra posición frente a la distinción entre filosofía política y ciencia política, clave epistemológica del arranque de la investigación; y, el segundo, trata de articular tres épocas del tomismo político contemporáneo (los primeros tres cuartos del siglo XX, último cuarto y contemporaneidad) en torno a las relaciones entre los conceptos de "bien común", lo "uno" y lo "múltiple".

Los mencionados ensayos pertenecen al "contexto de descubrimiento", según lo planteara Reichenbach en su Experience and Prediction (1938). En el aludido "contexto" de la ciencia encontramos la investigación en el siguiente estado: búsqueda, recolección de información y organización de datos.

Corresponde a un avance de investigación del proyecto intitulado Filosofía político-jurídica tomista en diálogo con la filosofía político-jurídica contemporánea, aprobado por la Facultad de Derecho en marzo de 2007, en la Línea de Investigación Institucional denominada: "Pensamiento ético, político, jurídico de Tomás de Aquino en contexto moderno y posmoderno".

** Docentes investigadores adscritos al Centro de Investigaciones Sociojurídicas Francisco de Vitoria de la Facultad de Derecho de la Universidad Santo Tomás; y miembros del Grupo de Investigación Raimundo de Peñafort clasificado categoría A por Colciencias (2006-2009).

1 Este paradigma se irá perfilando hasta perfeccionarse en la medida en que se vaya consolidando el proceso investigativo. 


\title{
Palabras clave
}

Contexto de descubrimiento, filosofía política, ciencia política, lo uno, lo múltiple, cuerpo político, justicia, bien común, Tomás de Aquino (TdA), Copleston, Lachance, Maritain, Chalmenta.

\begin{abstract}
Referring to four contemporary Thomistic political philosophers (Copleston, Lachance, Maritain and Chalmeta) we outline the paradigm of Thomas Aquinas' political philosophy that will serve as the basis for the dialogue with contemporary political philosophers. The sketch of the paradigm will take shape through the consolidation of the investigation process, which is in its initial phase. The present article includes two essays: The first one defines our position with regard to the distinction between political philosophy and political science. This question is the epistemological key for the start of the investigation. Focusing on the relations between the concepts of the common good, the singular and the universal, the second article discusses three phases of contemporary political Thomism (the first three quarters of the 20th century, the last one and the current period).

The above mentioned essays belong to the context of discovery introduced by Reichenbach in Experience and Prediction (1938). In the referred context of science, the investigation is in the following phase: search, collection of information and organization of data.
\end{abstract}

\section{Key words}

Context of discovery, political philosophy, political science, the singular, the universal, justice, common good, political body, Thomas Aquinas, Copleston, Lachance, Maritain, Chalmenta.

\section{INTRODUCCIÓN}

El Grupo Raimundo de Peñafort decidió iniciar la investigación de la filosofía política del aquinate, de cara al siglo XXI, a partir de una revisión del estado del arte que permitió a los investigadores Cárdenas y Guarín, designados para este proyecto por el raimundiano, sentar las bases del paradigma filosófico-político tomasiano, herramienta indispensable para el diálogo con los filósofos políticos contemporáneos.

Copleston y Chalmeta justifican la necesidad del "todo" para llevar al perfeccionamiento a cada uno de los individuos a través del bien común distribu- tivo, sin olvidar que sólo es posible alcanzar tal grado de perfección individual con la construcción del bien común colectivo, que depende de la dinámica armónica de las tres justicias. Las categorías de lo "uno" y lo "múltiple" lachancenianas les permitieron reconstruir las tensiones de la realidad política que unas veces recarga el poder sobre el individuo, y otras sobre el todo, sea social o estatal, dando origen, la primera, a teorías políticas individualistas que tienden a minimizar la importancia del todo, o en el caso de la segunda recarga del poder, a los totalitarismos. Los postulados de Maritain son presentados como herramienta hermenéutica 
clave para precisar la posición analógica tomista que precisa una tensión intermedia que depende siempre, y en todos los casos, de la "naturaleza de la cosa" política.

Utilizando la metodología de Tomás, parten, en primer lugar, de la ubicación epistemológica de la investigación en la "filosofía política", que, como lenguaje transdisciplinar, tiende a incluir todos los lenguajes de las ciencias auxiliares de la "ciencia política": economía política, sociología política, psicología social, politología, teoría del Estado, derecho constitucional, derecho público administración del Estado. Enseguida examinan el "bien común", en clave tomista, como la justificación de la existencia de las tensiones entre lo "uno" y lo "múltiple", que como realidades políticas son concreción de la dinámica de las fuerzas políticas individuales y colectivas por la pugna entre el interés particular y el interés común.

\section{FILOSOFÍA POLÍTICA Y CIENCIA POLÍTICA}

\section{Introducción}

El título de este ensayo sugiere un debate que recae sobre los contenidos específicos de dos formas de pensamiento distintas: la filosofía política y la ciencia política. ¿Cuáles son los objetos y los métodos de las dos?, ¿qué las separa?, ¿qué las une?, ¿en el lenguaje ordinario, qué sinonimias se dan?, ien el lenguaje técnico que giros lingüísticos se usan?

Existe una tendencia a considerar la filosofía política como una forma de reflexión no científica y, por lo mismo, no válida. Tal vez se deba al imperio de la filosofía idealista que maduró en la hipertrofia de la razón instrumental. Finalizando los setenta, y sobre todo en los ochenta, con el auge de las Ilamadas ciencias sociales, la situación se agrava hasta hacer sentir a los filósofos acomplejados de su saber. Las corrientes que tienden al cientificismo reductivo de origen positivista de todo saber, con desprecio de lo filosófico, le quitan al conocimiento su alma antropológica y ética. Además, atentan contra la independencia de los saberes, especialmente porque confunden los objetos y los papeles sociales de la filosofía política y la ciencia política. Con la tendencia creciente a recuperar la reflexión crítica de la política, que se hace desde el discurso filosófico, es decir, desde la ética, se recupera nuevamente el papel protagónico y subordinante de todo saber técnico que tiene la filosofía. Se propone tímidamente en este ensayo un equilibrio entre filosofía política y ciencia política.

\section{Las preguntas de la filosofía no son las mismas de la ciencia}

Las preguntas fundamentales que se hace el hombre son: quién es, de dónde viene y para dónde va. La filosofía pretende un saber universal y no un saber particular y especializado. ¿Qué es la ciencia? La ciencia no se pregunta por el porqué universal de las cosas, sino por lo que está ahí, por el ser aquí espaciotemporal de las cosas. La ciencia no pretende, entonces, un saber universal.

La ciencia se divide en ramas del saber respondiendo a la especialización que exige tener "ideas claras y distintas". Por lo demás, el científico necesita conocer el rumbo, y para ello recurre, de vez en cuando, al mapa de ruta variable establecido por el filósofo.

No se trata de relaciones de subordinación entre filosofía y ciencia, sólo de relaciones de carácter epistemológico, en las que la filosofía persigue el entendimiento de totalidad con conceptos de mayor extensión y menor comprensión. Y la ciencia pretende describir los fenómenos particulares hasta llegar a la máxima especialización. Como dice Bobbio (1997): "La diferencia entre el plano de la filosofía y el de la ciencia ya no es, en este caso, de naturaleza cuantitativa, sino exclusivamente de orden de importancia". 


\section{¿Qué relaciones hay entre filosofía y ciencia?}

1

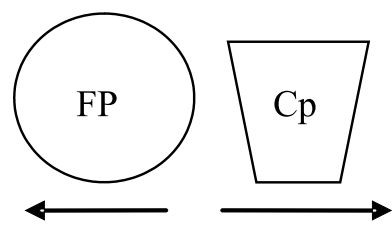

3

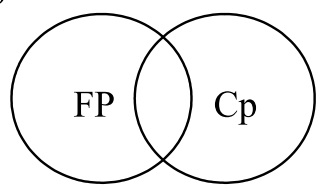

2
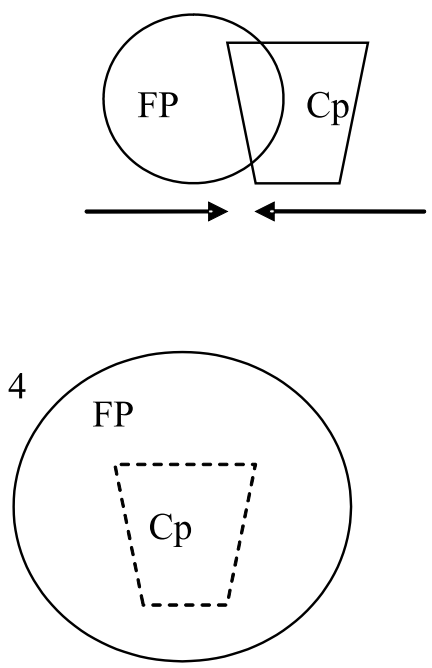

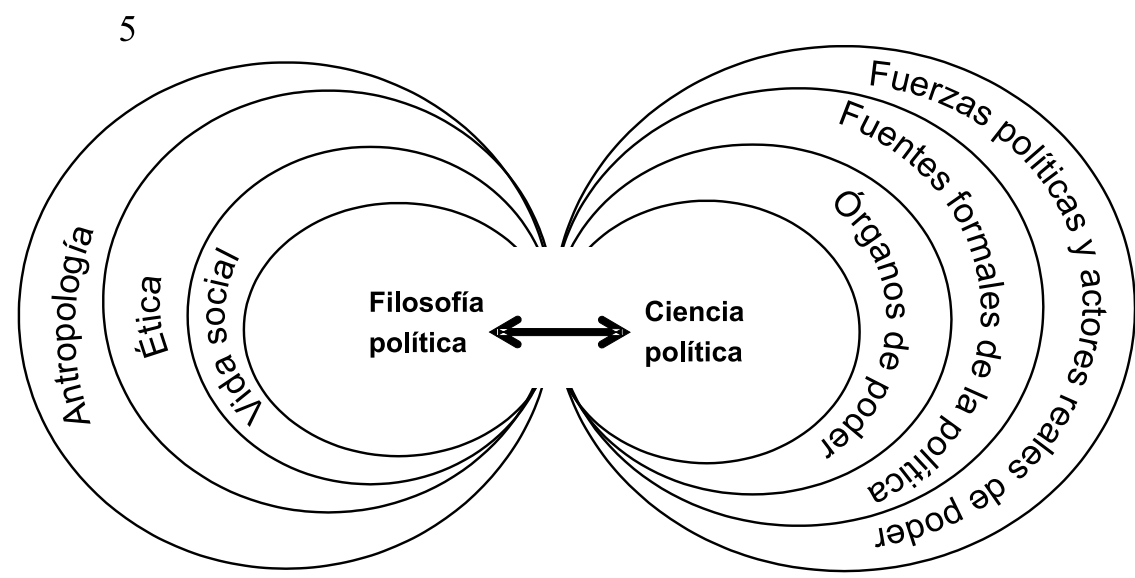

En los ideogramas podemos ver las relaciones que se pueden dar entre filosofía política (FP) y ciencia política (Cp): 1) separación y divergencia; 2) separación y convergencia; 3 ) continuidad; 4) subordinación y pérdida de identidad; 5) integración recíproca o de servicio mutuo.

La mayor separación se da entre las dos cuando la filosofía política asume una posición fuertemente valorativa; mientras que, por su lado, la ciencia po- lítica se especializa en el universo de los problemas técnicos o de procedimiento de la política.

La filosofía política es esencialmente un discurso ético, un discurso crítico del saber científico sobre el que vuelve para orientarlo señalando los fines educativos o reorientarlo cuando ha perdido el rumbo. En cambio, la ciencia política no pretende ese grado de universalidad porque sólo busca responder por el quien y el cómo y no por el porqué, propio de la filosofía. 


\section{ALGUNAS PROPUESTAS DE FILOSOFÍA POLÍTICA TOMISTA}

\subsection{Tomás de Aquino y el bien común como fin de la sociedad política ${ }^{2}$}

El ser humano es, para el maestro Tomás, una criatura creada a imagen y semejanza de Dios, una unidad de cuerpo y alma. En su concepción sobre el hombre, Tomás enfatiza en el ser personal de éste, es decir, toma en cuenta, tanto el aspecto orgánico y material del hombre -el cuerpo es un bien para el alma-, como el aspecto espiritual, al que llama "alma racional", que constituye ese elemento que está detrás de todas las actividades vitales del ser humano. Además, el hombre tiene una naturaleza social, que es fundamental para entender toda su teoría política y jurídica. Con base en esta concepción del hombre, se puede hablar de la vida moral, de la verdad, de la ley y de la sociedad política.

La conciencia y la libre elección de la que es capaz el hombre, manifiestan la dimensión de trascendencia sobre la materia que existe en él, lo cual no significa que esas actividades superiores -por lo menos en esta vida-, puedan ser ejercidas con independencia del cuerpo. Ahora bien, para Tomás, todos los seres humanos deseamos y buscamos eso que él denomina la "beatitudo" o felicidad, que para él connotaba ese bien que, al ser poseído, perfecciona las potencias del hombre. El bien no es otra cosa que aquello que perfecciona al hombre considerado como una totalidad, como una persona humana.

La opción por el bien se hace, según el aquinate, en el marco de la libertad. El hombre es un ser libre $y$, por ello, puede realizar "actos humanos" que corresponden a aquellas acciones de las cuales el

2 Las ideas desarrolladas en esta parte del artículo-avance, son producto de la analítica realizada a los textos de F.C. Copleston y Gabriel Chalmeta: "El pensamiento de Santo Tomás", "Historia de la filosofía" y "Justicia política en Tomás de Aquino", respectivamente. hombre es dueño por su razón y su voluntad; por eso define el libre albedrío como la facultad de la voluntad y de la razón, a la vez que afirma que sólo se podrán considerar como acciones propiamente humanas las que proceden de la voluntad deliberada, la cual siempre va precedida de un juicio de razón.

La reflexión sobre la vida moral del ser humano es hecha por Tomás en el marco de su deliberación sobre la acción del hombre, porque éste es acción libre, su conducta es moralmente buena o mala; la libertad es el presupuesto sine qua non se puede hablar de actos morales. Cuando Tomás habla de actos buenos y malos moralmente, se refiere en principio a actos interiores; sin embargo, si el acto interior resulta en uno exterior o así se considera, la palabra "acto" significa el conjunto de lo interior y lo exterior. En razón de su concepción teleológica de la naturaleza, Santo Tomás afirma que la voluntad humana está necesariamente dirigida hacia el fin último del hombre como tal y que hacemos nuestras elecciones particulares desde el impulso de esta orientación dinámica e innata de la voluntad. Todos los hombres apetecemos la realización de nuestra perfección; lo que varía de hombre a hombre es la realidad en la que se encuentra dicha perfección. Ahora bien, como es la razón la que permite actuar deliberadamente con vistas a un fin conscientemente aprehendido y la que lo eleva por encima del nivel de la conducta puramente instintiva, será la "recta razón" la que dirija los actos humanos hacia el logro del bien objetivo para él. Ese bien concreto y objetivo para el hombre sólo puede ser conocido por reflexión sobre su propia naturaleza humana tal como se conoce por la experiencia. Dicha reflexión conduce a Tomás -que es filósofo y teólogo-, a afirmar que el bien objetivo, universal y concreto para el hombre, no puede consistir en las riqueza ya que las riquezas son simplemente un medio para un fin; tampoco puede consistir en el placer sensible puesto que éste sólo perfecciona al cuerpo, no al hombre entero; ni puede consistir en el poder 
que no perfecciona a todo el hombre ni satisface completamente su voluntad y que, además, puede abusarse. Ni siquiera puede consistir en la consideración de las ciencias especulativas, puesto que es indudable que la especulación filosófica no satisface completamente al intelecto ni a la voluntad humanos. La perfecta felicidad, el fin último, no ha de buscarse en ninguna cosa creada, sino solamente en Dios, el Bien supremo e infinito: "el fin último y la felicidad del hombre deben consistir, pues, en la visión de Dios".

Un elemento importante de la vida moral del hombre es el hábito que se adquiere por actos repetidos de la misma naturaleza, y cuya consecución hacen que el hombre actúe rápida y fácilmente de cierta manera. La palabra hábito es neutra desde el punto de vista ético, pues pueden existir buenos o malos hábitos. Tomás llama "virtudes" a los buenos hábitos operativos y "vicios" a los malos.

Como Aristóteles, De Aquino distingue entre las virtudes morales, que inclinan al apetito sensitivo de un hombre a actuar de acuerdo con la recta razón y las virtudes intelectuales, que perfeccionan los poderes racionales de un hombre. A ellas hay que agregar las virtudes teologales, que ayudan al hombre a alcanzar su fin sobrenatural: la felicidad perfecta. Entre las virtudes morales e intelectuales, que constituyen el justo medio entre el exceso y el defecto, tiene especial importancia la virtud intelectual de la prudencia, la cual nos inclina a elegir los medios adecuados para el logro del bien objetivo, por lo cual dicha virtud se constituye en el punto de encuentro entre las virtudes morales y las intelectuales.

La propia naturaleza humana, que es racional, inclina al hombre a conocer la verdad. Ella es un resultado de la actividad del entendimiento, cuando el juicio que éste realiza se hace sobre la cosa tal como es. Así, la veritas está estrechamente vinculada con la cosa; de allí que surja de la conformidad del acto de entendimiento con la cosa: proportionem eius ad rem.
Santo Tomás se interesó siempre por la verdad, y creyó que el conocimiento de ésta se obtiene mejor por medio de la consideración desapasionada de las pruebas y argumentos que por llamamientos al corazón o a las emociones. En el marco de su meditación sobre el problema de la verdad, llegó a concluir que el material primario para su reflexión debería estar constituido por aquello que se capta por los sentidos. Para Tomás es natural que primero se preste atención a los datos obtenidos por la experiencia sensible; luego, a través del análisis metafísico, culminará con el conocimiento de aquello que está más alejado de la percepción sensible: Dios. En su reflexión sobre el tema de la verdad, manifiesta lo equilibrado de su pensamiento: no rechaza toda filosofía en nombre de la revelación, ni tampoco rechaza la idea de la revelación a nombre de la autonomía filosófica.

Una vez obtenida la percepción de las cosas por la vía de los sentidos, el hombre abstrae la esencia universal de la cosa de una idea particular, se hace una imagen y, luego, la imprime en el entendimiento. Así nace el concepto universal. La búsqueda de las categorías generales y los principios estructurales del ser, puesto que guardan proporción con el entendimiento humano, es tarea del metafísico. La mente humana puede aprehender proposiciones verdaderas, basadas, de alguna manera, en la experiencia, las cuales nos dicen algo acerca de las cosas, más allá de las palabras. En este sentido, Tomás representa el justo medio entre el empirismo y el racionalismo: él es del tipo de metafísicos que enuncian proposiciones generales sobre las cosas que nos son dadas en la experiencia. Esas proposiciones pretenden informarnos acerca de la estructura o acerca de las características esenciales de las cosas. En esta medida, el impulso básico del entendimiento es común al metafísico y al científico. Pero el primero se ocupa fundamentalmente de las cosas consideradas en su aspecto más amplio y general, es decir, como seres o cosas. En otras palabras, el metafísico se ocupa de la estructura categorial de la realidad empírica; el científico va a lo fenoménico. 
Todos estos elementos, que son fundamentales en la concepción antropológica tomasina, se completan con su idea de la naturaleza social del hombre. Y es justamente allí donde aparece el tema de lo político en Santo Tomás. La vida social está fundada en la naturaleza misma del hombre, y tanto la familia como el Estado son comunidades naturales. Contrario a lo sostenido por Agustín de Hipona, quien ve el Estado como una necesidad producto de la caída del hombre en el pecado (Civitas Diaboli) El maestro Tomás de Aquino enseña que

el hombre es por naturaleza un animal social. Por ello, en estado de inocencia los hombres habrían vivido igualmente en sociedad. Pero una vida social para muchos no podría existir si no hubiera alguien que los presidiera y atendiera al bien común [...] El gobierno es una institución natural, lo mismo que la sociedad, y por ello mismo, es algo querido por Dios (Aquino, Summa theologiae I, 96, 4).

Este texto de la Suma Teológica nos pone de presente que en el pensamiento de Santo Tomás el elemento clave de la sociedad política es la búsqueda, por parte de quien la preside, del bien común ${ }^{4}$. Aún más, como bien lo refiere Copleston, "el aquinatense habla de la función del Estado en términos de promoción del bien común" (Copleston, 2000: 263). La paz, la conducción a obrar el bien y el goce de las cosas que son necesarias para vivir bien, son los tres elementos que integran la

3 Recordemos que, contrario a los sostenido por Agustín, para Tomás, al crear al hombre, Dios quiso la sociedad humana y el gobierno político, y no tenemos derecho a decir que el Estado sea simplemente el resultado del pecado. Si nadie obrase mal, algunas actividades e instituciones del Estado se harían innecesarias; pero incluso en el estado de inocencia, si se hubiese mantenido, debería haber una autoridad que se cuidara del bien común.

$4 \quad$ El concepto de bien común, como acertadamente lo refiere G. Chalmeta en su texto sobre la filosofía política de Santo Tomás, es empleado por Tomás de Aquino en sus principales obras de filosofía política, a saber: el De regno o regimine principium, el Comentario a la Política que él escribió hasta el libro III lección 6, el Comentario a la Ética a Nicómaco y la segunda parte de la Summa Theologiae, todas ellas escritas después de 1265, en un período breve que permite acuñar como principio para leerle aquél según el cual "cada uno de los textos se puede interpretar a la luz del conjunto de todos ellos". noción de bien común, que están referidos por el propio Tomás en el texto de De Regno ${ }^{5}$. Como Aristóteles, Tomás nos habla de la función moral del Estado como promotor de la vida buena ${ }^{6}$. De este modo, el gobierno, como algo natural, existe para preservar la paz interna y para procurar la defensa de la comunidad, para promover el bienestar de los ciudadanos, en la medida en que esto puede ser hecho por una legislación apoyada en las sanciones, y para asegurarles la satisfacción suficiente de sus necesidades materiales ${ }^{7}$.

En ese sentido, es posible afirmar que la política liberal que limita la función del Estado a la mera vigilancia y dirección -la política del laissez faire-, no sería compatible con la concepción tomasiana sobre el propósito y función de la sociedad y el gobierno políticos. La tarea del Estado es producir activamente las condiciones en que pueda vivirse una vida humana plena. Empero, también son contrarias a su pensamiento las tendencias absolutistas que consideran que los poderes del Estado sobre sus miembros no tienen límites. No se puede perder de vista que para Tomás el hombre no es simplemente un miembro del Estado, y, en realidad, la cosa más importante para él es su vocación sobrenatural. Cualquier idea del soberano como completamente independiente e irresponsable es esencialmente extraña a la filosofía de Santo

5 En términos de Tomás, si se quiere alcanzar el bien común político, habrá de buscarse "la unidad a la que debe tender la ciudad". Unidad que se articula en dos momentos fundamentales: La unidad de la paz (De regno 1,3 ) y la vida buena de los súbditos (bienes materiales y espirituales). En De regno 1,3 afirma el aquinate que "el fin al que debe sobre todo mirar la persona que rige una comunidad política es la realización de la unidad de la paz". Paz amenazada desde el interior por la mala voluntad de algunos ciudadanos quienes violando la justicia turban la paz de los demás; $y$ del exterior porque existe siempre el riesgo de una agresión enemiga. Cfr. Chalmeta, G. p. 156 ss.

$6 \quad$ No sobre aclarar que, aunque Santo Tomás tomó muchas cosas de Aristóteles en lo referente al objeto y al método de estudio de la teoría política, consideró la materia a la luz de la perspectiva medieval cristiana, y modificó o complementó su aristotelismo de acuerdo con las exigencias de la fe cristiana. En fin de cuentas, la felicidad plena para Tomás solo se logra en el encuentro con Dios en la vida futura.

7 Copleston, Op. cit., p. 263 
Tomás. El soberano tiene sus deberes y los súbditos tienen los suyos: la "justicia legal", que debe existir tanto en el soberano como en los súbditos dirige todos los actos virtuosos hacia el bien común. Entre el fin sobrenatural y el natural del hombre debe haber la debida armonía, y la debida subordinación del segundo al primero; de modo que el hombre debe preferir a cualquier otra cosa la consecución de su fin último, y si el soberano le ordena obrar de una manera incompatible con la consecución del fin último, debe desobedecer al soberano. Toda idea de subordinación completa del individuo al Estado tenía que repugnar a Santo Tomás, no porque él fuese un extremado "papista" en los asuntos políticos (cosa que no era), sino por su sistema total filosófico-teológico. No puede haber, pues, "totalitarismo" alguno en Santo Tomás. Esto nos revela que, también en este punto, la filosofía de Santo Tomás es analógica, no de extremos univocistas y equivocistas.

Para la consecución de estos fines, la ley humana positiva es considera por Tomás como uno de los medios privilegiados con los que cuenta el gobernante. Dicha ley será auténtica en la medida en que se derive de la ley de la naturaleza; y si se aparta en un punto de la ley natural, ya no será ley, sino corrupción de la ley. La ley injusta impone cargas a los ciudadanos, no para el bien común, sino para satisfacer la avaricia del legislador. Frente a esas leyes, dice Tomás: "Tales leyes son más bien violencias [...] Por eso, no obligan en el foro de la conciencia, si no es para evitar el escándalo y el desorden" ${ }^{\prime 8}$. Empero, Tomás también habla en I-II, 96, 3, c, de otras vías para alcanzar los resultados de unidad de paz y bien material -léase "bien común"-; entre ellas están la adopción de todas las medidas jurídicas que favorezcan la buena educación que prepara a los ciudadanos para que conserven el bien común de la justicia y de la paz. Y en el comentario a la ética a Nicómaco, nos dice que la sociedad política cuenta con dos instrumentos jurídicos fundamentales de los que puede valerse para alcanzar el bien común: las normas y los actos jurídicos que emanan de la autoridad, especialmente las leyes, que contribuirán a la realización del bien común político, puesto que con la amenaza de las penas se frena a los jóvenes rebeldes que no se corrigen con las admoniciones paternas ${ }^{9}$. Finalmente, en otros apartes de la Suma Teológica, además de las leyes, habla de la costumbre social como "regla" de comportamiento para la realización de los intereses públicos, nacida espontáneamente de la vida social misma. Lo dice 33 veces, en seis artículos ${ }^{10}$.

Respecto a la forma que debe asumir el gobierno para alcanzar el bien común, es claro que para el aquinatense ninguna forma particular es ordenada por Dios para todos los hombres; empero, se inclinó por una constitución mixta, en la que el principio de unidad, representado por la monarquía -a la postre es la forma más natural de gobierno por analogía con el dominio de Dios sobre la creación- se combina con el principio de administración por los mejores y con cierta medida de control popular. Podríamos decir, en términos modernos, que Tomás estaba a favor de la monarquía constitucional, sin perder de vista que la razón de ser de dicha organización es que la autoridad se consagre a cuidar y promover el bien común. En efecto, el Estado es una communitas perfecta, es decir, tiene a su disposición todos los medios necesarios para la consecución de su propio fin, el bonum commune de los ciudadanos. Como se refería ut supra, la consecución del bien común exige la paz en el Estado, la dirección unificada de las actividades de los ciudadanos ad bene agendum y la provisión adecuada frente a las necesidades de vida. El gobierno del Estado se instituye para asegurar esas condiciones necesarias para la consecución de ese bien común. 
Santo Tomás insiste también en su reflexión sobre el bien común, en que es necesario, para que se alcance, que los obstáculos para la buena vida tales como el peligro de los enemigos de fuera y los efectos desintegradores del crimen en el interior del Estado, sean superados, y el monarca tiene a su disposición los medios necesarios para hacerlo, a saber: las fuerzas armadas y el sistema judicial. Ahora bien, cuando el monarca busca el bien común de la multitud, busca igualmente su propio bien, puesto que el propio bien no puede conseguirse a menos que se consiga el bien común. En consecuencia, el gobernante no posee su soberanía sino para el bien de todo el pueblo, y no para el bien privado, y, si abusa de ese poder, se convierte en tirano. Respecto a la actitud que la comunidad ha de asumir frente al tirano, Copleston pone de manifiesto que

\begin{abstract}
el asesinato del tirano fue condenado por Santo Tomás, el cual habla con cierta extensión de los males que pueden resultar de las rebeliones contra los tiranos. Por ejemplo, el tirano puede hacerse más tiránico si la rebelión fracasa, mientras que ésta tiene éxito, puede no tener otra consecuencia que la substitución de una tiranía por otra. Pero la deposición del tirano es legítima, especialmente si el pueblo tiene derecho a procurarse un rey. En tal caso, el pueblo no hace mal al deponer al tirano, aunque se hubiese sometido a éste indefinidamente, ya que el tirano ha merecido ser depuesto al perder la fidelidad que debía a sus súbditos ${ }^{11}$.
\end{abstract}

No sobre enfatizar en que, para Santo Tomás, la vida en sociedad es un bien social o común en sí mismo, al punto que el vivir bien individual es, en sí mismo, un vivir bien junto a otros (Chalmeta, 2000: 157). Santo Tomás es de la idea según la cual "la felicidad humana está estrechamente ligada a la amistad y el amor, verdadera amistad en la virtud en donde se quiere el bien del otro y se participa de él como si fuera bien propio, y se

11 Ibíd., p. 406 da de manera recíproca (requeritur mutua amatio)" (Ibíd.: 159). Así, la sociedad política se dirige, por último, al compromiso amistoso del sujeto: el bien común de la sociedad política. Se trata de la amisticia concivium.

Como bien lo refiere Chalmeta en los inicios de su análisis sobre la justicia política en Santo Tomás, las obras políticas del aquinate admiten un tipo de "lectura" del que emergen algunos principios muy generales de justicia político-jurídica, a partir de los cuales el intérprete actual puede -sin forzar las cosas- desarrollar una reflexión capaz de superar con la cabeza bien alta la confrontación dialéctica con las propuestas políticas modernas y posmodernas de matriz utilitarista o contractualista, y contribuir positivamente así a la solución de los problemas del Estado liberal democrático y a la construcción de una sociedad política más justa en el futuro. La época de "renacimiento medieval" en la que tuvo que vivir el aquinate, le dio la posibilidad de reflexionar sobre temas que han trascendido la historia -desde los griegos, pasando por los romanos y por la época medieval- y que hoy se encuentran a la orden del día en materia de filosofía política.

\section{Conclusión}

Fundamentalmente, el principio del "bien común político" sobre el que hemos reflexionado a lo largo de estas líneas constituye la "bóveda de la concepción política del aquinate", que es un foco que ilumina con su luz radiante, la realidad política contemporánea, más aún cuando desde hace unas décadas asistimos a la crisis, y consecuente decadencia, del Estado liberal democrático, que se había formado esencialmente con el impulso de la doctrina política utilitarista a partir de la segunda mitad del siglo XIX. Con la guía del modelo liberal de justicia política, que hoy está en crisis, se han obtenido importantes conquistas en el ámbito de afirmación de libertades individuales y de solidaridad política. Sin embargo, el uso de la racionali- 
dad matemática que impone el utilitarismo lleva a tener que sacrificar el bien de un individuo o de una minoría para obtener el bien de un grupo más numeroso de personas: y esa conclusión es insensata e inaceptable. El pensamiento de Tomás emerge, en este contexto, como un oasis en el desierto, con un agua limpia, de la cual todos podemos beber.

Pero el pensamiento del de Aquino también da luces frente a las propuestas que plantean las tesis neocontractualistas actuales, como la de John Rawls. Estas nuevas propuestas afirman de manera consciente que la racionalidad política exige una relación entre el bien y la justicia, que sea la exacta antítesis del utilitarismo; para ello proponen la prioridad de la noción de justicia sobre la de bien. Lo que se quiere afirmar es la idea de que las relaciones sociales deberían estar ordenadas según una serie de principios de justicia política que no presupongan ninguna concepción ética específica de los ciudadanos, o dicho de otro modo, que es preciso que los principios que modelan la vida política sean compartidos por todos los ciudadanos, independientemente de la concepción ética que profesen, esto es, la respectiva visión sobre la vida buena y, en último análisis, sobre la naturaleza de la felicidad humana.

Sin embargo, las tesis contractualistas también han arrojado frutos negativos: las políticas no discriminantes y las acciones positivas en favor de las minorías amenazan toda libertad en nombre de la igualdad. De otra parte, las tesis puramente procedimentalistas -y entre ellas el contractualismo- son muy peligrosas si no se fundamentan en criterios que refieran a contenidos de carácter material. Al respecto, Tomás nos enseña que la filosofía política tiene como objetivo conocer la verdad sobre la justicia política, esto es, saber el mejor modo de estructurar las relaciones entre los ciudadanos, de suerte que leyes e instituciones que sean injustas -que atenten contra la persona- deben ser abolidas o reformadas. Y es que Tomás de Aquino, con su característico pensamiento analógico plasmado en su noción de "bien común político", presenta una vía intermedia entre los extremos del utilitarismo y del contractualismo. Por eso hoy tiene sentido estudiar su propuesta política, porque él también tiene una concepción sobre la verdad que busca la filosofía política, según la cual la comunidad debe respetar el fin del individuo -esa sería una sociedad justa- pero, también los individuos deben ajustar sus fines al de la comunidad, esto es, promoviendo el bien de los otros. La filosofía política del aquinate parte de la base de que la felicidad humana, fin de toda existencia personal y social; está estrechamente ligada a la amistad y el amor, como se refirió líneas atrás. Una sociedad política es justa cuando hay respeto y promoción del bien de cada hombre, ya que cada persona ha de ser considerada como un valor absoluto, un "todo" metafísico y moral.

\subsection{La relación analógica entre lo "uno" y lo "múltiple", base del "cuerpo político", primera clave de la filosofía política tomista ${ }^{12}$}

En este ensayo trataremos de investigar si el todo (estatal o social) es una objetividad distinta de la de sus miembros, si se confunde con el realismo de los individuos o si representa un modo propio de ser.

\subsubsection{Lo uno y lo múltiple: tensiones y distensiones}

La idea de investigar las relaciones entre lo "uno" (individuo) y lo "múltiple" (el todo social o estatal) ha sido uno de los intereses de la labor científica del pensamiento filosófico-político desde la antigüedad $^{13}$. La especulación política ha tenido que

12 Las ideas desarrolladas en esta parte del artículo-avance, son producto de la analítica realizada a los textos de Louis Lachance y Jacques Maritain: El humanismo político de Santo Tomás y El hombre y el Estado, respectivamente.

13 A propósito precisa Lachance: "La idea de querer comparar el individuo y el Estado no es nueva. Es tan antigua como la labor científica del pensamiento filosófico. Se ha manifestado en casi todas las épocas desde la aurora de la especulación política hasta nuestros días" (p. 245). 
precisar distinguiendo varios conceptos que representan el "fenómeno político": la que define lo "uno" con: el individuo, la persona o el ciudadano; y la que definen lo "múltiple" con: el pueblo, la comunidad, la nación, el cuerpo político, la sociedad perfecta, la sociedad política o el Estado, etc. No se trata, al presentar los dos extremos de la relación política (lo "uno" y lo "múltiple"), de una evolución cualitativa y jerarquizada de estos conceptos, como si lo "múltiple" fuera mejor que lo "uno", sino de una presentación en orden a establecer qué tipo de relaciones que hay entre ellos.

Lo "múltiple" para que funcione debe constituirse en la "unidad" del todo en un proceso razonado de unificación de necesidades e intereses políticos sin que las partes pierdan su identidad y se confundan con el todo. Hay que precisar que para Aristóteles, si el proceso de unificación se lleva a cabo con demasiado rigor, ya no habrá más Estado: pues la "ciudad" es por naturaleza una "pluralidad" y no una "unidad", como lo es el "individuo". Así, si el Estado dejara de ser "pluralidad" y pasara a ser "unidad" compacta, perderían identidad sus "partes individuales", llegando a confundirse él; e incluso se daría la posibilidad de ciertas partes fueran sacrificables si no se ajustan al todo, como sucede en los totalitarismos ${ }^{14}$. Lachance (2001), comentando este pasaje de La Política en comparación con el pensamiento político de Platón, concluye así:

\begin{abstract}
Para Aristóteles, lo uno en sentido absoluto es el individuo, mientras que, según la visión de Platón, es el Estado. Éste llega a profesar que el individuo es absorbido por la colectividad en tal grado que de su conjunción resulta una entidad única En consecuencia, la acción de individuo y la colectividad se confunde hasta el punto de formar el objeto de un mismo y único saber (p. 24)
\end{abstract}

Para el estagirita el Estado tiene unidad relativa. Lo "uno", aunque comprendido en lo múltiple, no desaparece en él. Esto permitió a Aristóteles separar la ética de la política. Al respecto, Lachance (2001) dice lo siguiente: "el estagirita fue el primero en separar la ética de la política, confiando a la primera el cuidado de estudiar la actividad de lo uno y abandonando a la segunda el de dirigir la de lo múltiple" (p. 25).

En la comprensión de la sociedad y del régimen político en torno a lo "uno" y lo "múltiple", Tomás de Aquino ensaya las tres metodologías: la univocista, la equivocista y la analógica. A la univocista parece referirse con la siguiente afirmación en apariencia totalitaria: "Totus homo ordinatur ut ad finem ad totam communitatem cuius est pars" ("Todo el hombre se ordena como a su fin a toda la comunidad política de la que es parte") (Aquino, Suma Teológica, II-II, 61, 1; 64, 2 y 5; 65, 1). A la equivocista parece aludir cuando habla de las individualidades solitarias, comparables a la existencia de hombres disímiles: el santo perfecto, el héroe, el salvaje bestial o fiero (Aquino, Comentario a la política. L., I, Lec. 1). Pero, sin duda, termina prefiriendo la metodología analógica, de máximo rendimiento ético: "Homo non ordinatur ad communitatem politicam secundum se totum et secundum omnia sua" ("El hombre no se ordena a la comunidad política según todo él y según todo lo suyo" ${ }^{15}$. Lachance complementa de la siguiente manera:

Se llegó a la conclusión de que el hombre, en tanto que es persona, no entra en comunidad, sino solamente en tanto que es individuo. En tanto que persona, es un todo que es un fin en sí, pero en tanto que individuo, es solamente parte de la sociedad política. La personalidad y la individuación ejercen en él tensiones opuestas: la primera solicitándolo hacia la eternidad, la segunda reteniéndolo en la zona del tiempo (2001: 45).

La relación entre dos términos puede ser lógica o real. En el caso del vínculo entre lo "uno" y lo 
"múltiple", en contexto político, tenemos una relación de tipo real cuya unidad expresa una consistencia también real. Como el "todo" depende su existencia de la integración de sus "partes", podemos afirmar que el realismo de lo "múltiple" está dado por el realismo de lo "uno". Lachance concreta la idea de la siguiente manera:

Y por lo que se refiere al caso que ahora nos ocupa, ya sabemos que el principio elemental del Estado, la persona humana, es un término bien real. Podríamos ya presumir el realismo del otro término, el Estado, pues el todo resulta de las partes que lo componen (2001: 245).

\subsubsection{Si la forma superior de la solidaridad es la sociedad política}

Para Aristóteles, los conceptos de "benevolencia" y "amistad" nos permiten pensar que en él ya había la intuición de la distinción entre lo político y lo social. Sin embargo, es Tomás de Aquino quien va a desarrollar la separación precisando la concepción del instinto social del estagirita. La distinción entre filosofía social y filosofía política en el aquinate debe concluir con una visión integradora tal y como lo pensaba Maritain: "distinguir para unir".

La analogía de las relaciones entre persona y sociedad política, cuando TdA se pregunta si la ley está ordenada al bien común, comprobamos que éste es el fin de la "sociedad perfecta", pero que está inscrito en un nuevo bien común superior que se identifica con el fin último del hombre, $y$ que se encuentra en un plano al que Aristóteles no arribó jamás, y donde ni la polis ni la política ocupan el primer puesto, sino que resplandece la sociedad universal ("communitas universi"). Aquí TdA teólogo ha superado al simple comentador de las obras de Aristóteles.

El mediador que da el gran impulso transformador de la política clásica en la moderna filosofía social ${ }^{16}$, entre Aristóteles y Hobbes, fue Tomás de Aquino. A éste se debe que la comunidad social no se reduzca a la sociedad política. La persona existe primero como ser social antes que como ser político, y sus intereses sociales pueden colisionar con el poder del régimen político.

Al respecto, Jürgen Habermas precisa:
Una comunidad sólo puede denominarse Estado si habilita a sus ciudadanos para acciones virtuosas $y$, en esta medida, para la vida buena. Pero, por otra parte, Tomás de Aquino ya no entiende esta comunidad de una forma genuinamente política: la civitas se ha convertido su- brepticiamente en societas. El distancia- miento respecto a la antigua política no se muestra en ninguna otra parte de una forma más precisa que en la traducción textual del zoon politikon: "Homo natu- raliter est animal sociale". En otro lugar se dice: "Naturale autem est homini ut sit animal sociale et politicum" [...] "Thema probandum de las reflexiones justamente denominadas "filosófico-sociales" de la "política" tomista es, más bien, un orden doméstico y familiar extendido al Estado, es la jerarquía del estatus del ciudadano que trabaja. El ordo civitatis abarca el trabajo rehabilitado por el cristianismo, que para los griegos era un campo absolutamente apolítico (1995: 54-70).

Y concluye el filósofo de Frankfurt considerando al aquinate como fundador de la filosofía social: "Así pues, Tomás de Aquino transforma la política aristotélica en una filosofía social; en cualquier caso, mantiene la tradición en la medida en que se atiene a aquella conexión entre ética y política tan claramente acuñada por Aristóteles" (Habermas, 1995: 70).

16 Véase Habermas, Jürgen, Teoría y Praxis: Estudios de filosofía social, Altaya, 1995, pp. 49 y 50. Hobbes, en la mitad del siglo XVII, "ya no cultiva la "política" al modo aristotélico, sino la social philosophy." [...] "La antigua política se ha convertido en algo extraño para todos nosotros, en una triple perspectiva": (1. la moralidad está desprendida de la legalidad, así como la política está de ambas; 2 . ahora la política si tiene que ver con la techné; y 3. la política se conoce a partir de la esencia de la justicia: las leyes y los pactos). 
Según Aquino, de los valores de convivencia y coexistencia el más perseguido es la solidaridad y resulta, además, el que justifica la integración de los demás valores del plexo coexistencial (paz, poder, orden, seguridad, etc.), porque se basa en la "inclinación natural del hombre a vivir en sociedad". La persona es, pues, "soporte material y causa realizadora del orden social... esa forma superior de solidaridad que es la sociedad política". (Lachance, 2001: 253).

Para producir la "perfección plenaria del hombre", última finalidad de la persona, la razón deduce la necesidad del orden social como medio o instrumento necesario. La solidaridad está acompañada, para lograr el proyecto compartido de vida social, de los demás valores de coexistencia y de convivencia: paz, seguridad, poder, orden, cooperación forzosa, y los valores fundantes justicia y bien común.

\subsubsection{Si la justicia y el bien común son valores de la proyección de lo "uno" en lo "múltiple"}

Jacques Maritain nos presenta su filosofía política a partir de las relaciones entre seis aspectos de la compleja realidad política pueblo: comunidad, nación (y clase), sociedad, cuerpo político (sociedad política), Estado. Tratando de integrar estas categorías precisaremos hasta dónde lo "uno" y lo "múltiple" funcionan como extremos para el análisis de las sociedades políticas contemporáneas.

Los elementos del concepto "pueblo", como la primera expresión de lo "múltiple" en Maritain (1993), son: a) multitud de personas humanas; b) unidas bajo leyes justas; c) para el bien común de su existencia humana; d) constituyen una sociedad política o cuerpo político. El centro articulador de tales elementos es la amistad, que en términos del aquinate, se traduce en la natural familiaridad que tenemos con los demás: "todo hombre debe ser para todo hombre un familiar y amigo" (Aquino, Suma Contra Gentiles. L. III, Cap., 117). "Pueblo" es la principal categoría mariteniana pues constituye "los huesos y la carne" de la comunidad y la sociedad. "El pueblo -en palabras de Maritain- es la multitud de las personas humanas que, unidas bajo leyes justas por amistad recíproca y para el bien común de su existencia humana, constituyen una sociedad política o un cuerpo político" (Maritain, 1993: 39).

El "pueblo" organizado inconcientemente como colectivo se convierte en Comunidad. Ésta es la primera categoría de "política organizada" y surge de un hecho anterior a toda determinación y voluntad humana. Se trata de un fenómeno organizativo inconsciente. De la simple interacción natural de las tres justicias surge esa organización activada por todos en su vida diaria. Al respecto precisa Maritain: “En una comunidad el objeto es un hecho que precede a las determinaciones de la inteligencia y de la voluntad humanas y que actúa independientemente de ellas para crear una psiquis común inconsciente, estructuras psicológicas y sentimientos comunes, costumbres comunes" (Ibíd.: 17).

La "nación", segunda categoría mariteniana, es una forma de comunidad que tiene un principio organizador basado en la cultura de un pueblo, es ese entramado de mentalidades, creencias e ideas que permiten identificar y diferenciar una multitud humana de otra. La vida política se conoce por el funcionamiento de su régimen político. Y éste se puede visualizar como un movimiento que arranca desde la nación, cuyas mentalidad y creencias le permiten autocomprender sus necesidades e intereses (vehiculados y socializados por lenguajes e imaginarios), materia prima o insumos que ingresan en la dinámica transformadora de un proceso que puede representarse mediante dos embudos contrapuestos: el de entrada o input, que parte de los más a los menos y se va reduciendo sustitutivamente (por grados de representatividad ciudadana) desde las bases del poder electoral hasta llegar a las colectividades o individualidades 
competentes para el ejercicio del poder (cuerpos legislativos, ejecutivo). Las necesidades e intereses del input, por la alquimia de los representantes se traducen en ideas políticas y jurídicas (movilizadas por los imaginarios de los medios de comunicación), que, gracias al monopolio del poder de los órganos del Estado, se convierten en normas jurídicas e instituciones (producto o output) que vuelven a la nación (de los menos a los más) como decisiones responsivas o presuntas soluciones. Éstas, al contrastarse con las expectativas colectivas y agregadas a nuevas necesidades e intereses, recomienzan el proceso: la dinámica del régimen político lo convierte en un perpetuo recomenzar a lo Sísifo, cuyo "a quo" impulsa la vida política y cuyo "ad quem" hace siempre provisionales las respuestas, de tal modo que éstas deben rodar de nuevo a la sima insatisfecha de la nación.

\section{Según Maritain:}

La Nación es una de las comunidades más importantes, acaso la más completa y compleja de las comunidades engendradas por la vida civilizada. Los tiempos modernos se han encontrado en presencia de una tensión y un conflicto entre la Nación y otra comunidad humana de crucial importancia: la clase. Es, sin embargo, un hecho que el dinamismo de la Nación es el que se ha mostrado más poderoso, porque está más hondamente enraizado en la naturaleza (1993: 19).

La "sociedad", tercera categoría de Maritein, a diferencia de la comunidad, es la política organizada racionalmente en torno al bien común. Maritain precisa: "En una sociedad el objeto es una tarea que cumplir o un fin que lograr, que dependen de las determinaciones de la inteligencia y de la voluntad humanas y que van precedidos por la actividad (decisión o, por lo menos, consentimiento) de la razón de los individuos" (Ibíd.: 17).

El "cuerpo político", cuarta categoría mariteneana, es sinónimo de sociedad política. Y, como diría Lachance, es la máxima expresión de la solidari- dad humana. El cuerpo político es el todo unitario compuesto por el pueblo. La comunidad y la sociedad son, una y otra, realidades ético-sociales verdaderamente humanas y no sólo biológicas. "Pero una comunidad -aclara Maritain- es ante todo obra de la naturaleza y se encuentra más estrechamente ligada al orden biológico" (Ibíd.: 13). El Estado es un instrumento del cuerpo político que busca garantizar el orden público con miras a la obtención del bien común. El regulador de la actividad del Estado, que evita su transformación en un "todo absorbente", es el acto justo de sus partes y la acción justa entre lo "uno" y lo "múltiple". La justicia es un fenómeno único en el que identificamos tres dimensiones que tienden a ser escindidas en los individualismos o en los totalitarismos. Para comprender la dinámica de la justicia es necesario precisar la función de cada dimensión. Las tres justicias (o dimensiones de la justicia) resultan correlativas, de tal manera que se intercondicionan en su dinamismo: la general, en la medida en que compromete las acciones de todos en el aporte de las cosas que se deben a la construcción del "bien común", garantiza la eficacia de las distintas formas de "dar" de la distributiva; ésta, a su vez, da las cosas indispensables (según criterios de dignidad, mérito, capacidad, necesidad) que pueden convertir a los miembros de la sociedad en sujetos capaces de los intercambios de bienes regulados por la conmutativa.

Una sociedad política puede diferenciarse progresivamente en el seno de una vida social confusa en que las funciones políticas y las actividades comunitarias se hallaban en un principio mezcladas. La idea de cuerpo político puede surgir en el interior de una comunidad nacional; más la comunidad nacional no puede ser más que un suelo propicio y una ocasión para este desarrollo. En ella misma, la idea de cuerpo político alude a otro orden, que es superior. $Y$, en cuanto el cuerpo político toma forma, éste se distingue de la comunidad nacional. 
Para Maritain el "Estado", séptima categoría mariteniana, se convirtió en la suprema encarnación de la "Idea", tal y como lo creía Hegel. En "una especie de superhombre colectivo". Mas, realmente el estado "no es más que un órgano habilitado para hacer uso del poder y la coerción y compuesto de expertos o especialistas en el orden y el bienestar públicos" (Maritain, 1993: 26). El cuerpo político y el Estado aluden al orden en su "forma más elevada" o "perfecta". La nación alude a un orden de hecho inconsciente arraigado en el nivel de las creencias y las mentalidades.

Representémonos, a manera de conclusión, este esbozo de la filosofía política de Maritain:
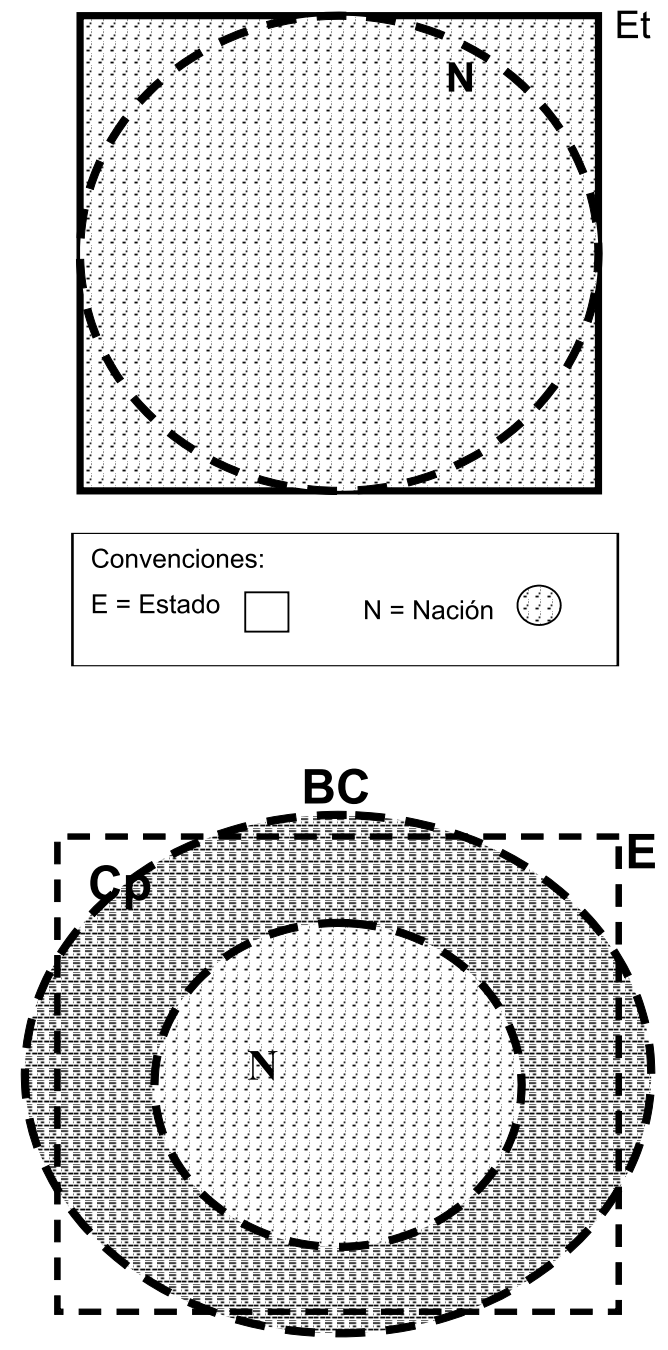


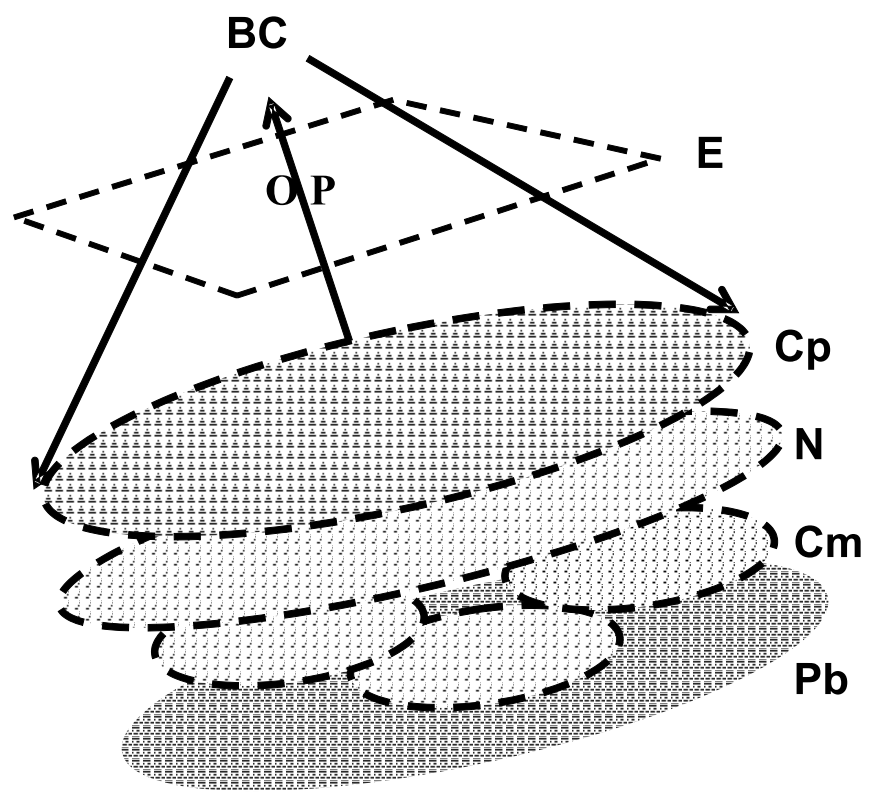

Convenciones: $\mathrm{Pb}=$ Pueblo; $\mathrm{Cm}=$ Comunidad; $\mathrm{N}=$ Nación; $\mathrm{Cp}=$ Cuerpo político (Sociedad política); $\mathrm{E}=$ Estado; $\mathrm{OP}=$ Orden público; $\mathrm{BC}=$ Bien común.

El primer ideograma represente el Estado totalitario (Et) que confunde la Nación ( $\mathrm{N}$ ) con el aparato estatal. Esta es la base de la crítica que hace Maritain desde la Europa de postguerra. Vemos la cohesión entre los sujetos nacionales formando un todo compacto en dos dimensiones estructurando el Estado hasta el punto de reducir a un cierto grado de subordinación la Nación misma.

En el segundo ideograma Maritain presenta un estado instrumental subordinado al cuerpo político ("sociedad perfecta") que organiza racionalmente los intereses comunitarios (nacionales y de pequeñas comunidades) entorno al bien común. Ser trata de una visión tridimensional y en espiral del fenómeno político. Las costumbre y tradiciones del pueblo $(\mathrm{Pb})$ es la base de todo fenómeno comunitario $(\mathrm{Cm})$; la Nación $(\mathrm{N})$ es el máximo fenómeno comunitario. El "cuerpo político" (Cp) es la sociedad madura que ha llegado al máximo grado de "racionalización de la vida política". Es la "sociedad madura" que crea el Estado (E) como instrumento para garantizar el orden público (Op) de camino al Bien Común (BC).

Las categorías de lo "uno" y lo "múltiple" lachancenianas y las seis de Maritain, nos permitieron reconstruir las tensiones de la realidad política que unas veces recarga el poder sobre el individuo y otras sobre el todo, ya social o estatal; dando origen, la primera recarga del poder, a teorías políticas individualistas que tienden a minimizar la importancia del todo o, en el caso de la segunda recarga del poder, a los totalitarismos. 


\section{BIBLIOGRAFÍAS}

\section{Obras tomasinas}

AQUINO, Tomás de. Suma Teológica. (1988: I Tomo; 1989: II Tomo; 1990: III Tomo; 1994: IV y V Tomos). Dirigida por los Regentes de Estudios de las Provincias Dominicanas de España. Madrid: BAC.

(1967). Suma Contra Gentiles. Texto latino al cuidado de la Orden de Predicadores con traducción y notas introductorias de Laureano Robles Carcedo, O.P., Adolfo Robles Sierra, O.P., y José M. De Garganta, O.P., (segunda edición), Madrid: BAC (dos tomos).

(1998). Traducción y estudio introductorio de Carlos Ignacio González, S.J. México: Porrúa (edición íntegra en un tomo).

. (2003). La Monarquía. Al Rey de Chipre (Régimen de los Príncipes). Opúsculos y cuestiones selectas, Coordinación Antonio Ossuna Fernández-Largo, Madrid: BAC (Maior).

(2001). Comentario a la Política. (ALVERNIA, Pedro de) traducción de Ana Mallea. Pamplona: EUNSA.

\section{Obras tomistas auxiliares}

COPLESTON, Frederick. (2004). Historia de la Filosofía. Barcelona: Ariel. (2000). El pensamiento de Santo Tomás. Breviarios. México: Fondo de Cultura Económica.

CHALMETA, Gabriel. (2002). La justicia política en Tomás de Aquino: una Interpretación del bien común político. Pamplona: EUNSA.
LACHANCE, Louis. (2001). Humanismo político: Individuo y Estado en Tomás de Aquino. Pamplona: EUNSA.

MARITAIN, Jacques. (1997). El hombre y el Estado. Madrid: Encuentro.

PIEPER, Josef (1998). Las virtudes Fundamentales. Madrid: Rialp.

\section{Otras obras utilizadas en este artículo}

ARISTÓTELES, (2000). La Política, Versión directa del original griego, prólogo y notas de Manuel Briceño Jáuregui, S.J. Bogotá: Panamericana. En comp. con trad. de (2005). Madrid: Centro de Estudios Constitucionales y Políticos, Sexta edición.

BOBBIO, Norberto; MATTEUCCI, Nicola; PASQUINO, Gianfranco. (2002). Diccionario de Política. México: Siglo Veintiuno.

(1997), El filósofo y la política. Antología. (Fernández Santillán, José, compilador), texto "Sobre las posibles relaciones entre filosofía política y ciencia política" (1970), Fondo de Cultura Económica. México, p. 58.

HABERMAS, Jürgen. (1995). Teoría y praxis: Estudios de filosofía social. Barcelona: Altaya.

REICHENBACH, (1998). Experience and Prediction. New York: Edt. Ash. 